\title{
ESTUDIOS
}

\section{De la norma al ordenamiento jurídico: aspectos de la doctrina jurídica de Francisco Suárez}

\author{
Antonio E. Pérez Luño'
}

Resumen: Francisco Suárez es un autor clásico de la teoría jurídica. Este trabajo expone como en la obra suareciana ya se encuentran elementos que lo sitúan como precursor del pensamiento jurídico moderno. El artículo destaca el valor de la obra fundamental jurídica de Suárez De legibus, que adelanta el elemento de sistematicidad del derecho, superando una visión del derecho meramente como normas aisladas. También se expone como en el pensamiento jurídico de Francisco Suárez se presenta una conexión del derecho con la dimensión social vinculándola como precedente de la propuesta del institucionalismo jurídico contemporáneo.

Palabras clave: escuela española del derecho natural y de gentes (ius gentium), Francisco Suárez, institucionalismo, ordenamiento jurídico.

Fecha de recepción: 28 de septiembre de 2016.

From rules to the legal system: aspects of the legal doctrine of Francisco Suárez

Abstract: Francisco Suárez is a classic author of legal theory. This paper shows that the Suarez's work already contains elements that place him as precursor of the modern legal thought. This article highlights the
De la norme au système juridique: aspects de la doctrine juridique de Francisco Suárez

Résumé: Francisco Suárez est un auteur classique de la théorie juridique. Ce travail expose comment, dans l'œuvre de Suárez, nous pouvons trouver déjà les éléments qui le situent comme précurseur de la pensée

1 Departamento de Filosofía del Derecho. Universidad de Sevilla. Este artículo se enmarca en el Proyecto de l+D+l "Pensamiento y tradición jesuita y su influencia en la modernidad desde las perspectivas de la Historia, la Traductología y la Filosofía Jurídica, Moral y Política", FFI2015-64451-R (MINECO/FEDER). 
value of the Suárez's seminal legal work De legibus, which advances the systematicity of law, abandoning a vision of law merely as isolated rules. This article also shows how the legal thought of Francisco de Suárez presents a connection between law and the social dimension as the precedent of the proposal of the contemporary legal institutionalism.

Key words: Francisco Suárez, institutionalism, Spanish school of natural law and law of nations (ius gentium), legal order. juridique moderne. L'article meten valeur son œuvre juridique fondamentale, "De legibus», qui annonce l'élément de systématicité du droit, dépassant une vision du droit comme l'application exclusive de normes isolées. Le texte expose également de quelle façon est présente une connexion du droit avec la dimension sociale dans la pensée juridique de Francisco Suárez, en en faisant un précurseur de la proposition d'institutionnalisme juridique contemporain.

Mots clé: École espagnole du droit naturel et du droit des gens (ius gentium), Francisco Suárez, institutionnalisme, ordination juridique.

\section{El ideario jurídico de Francisco Suárez y su persistente actualidad}

A lo largo de las distintas épocas que conforman la evolución de los sistemas jurídicos, tienen lugar acontecimientos y experiencias que guardan entre sí una evidente analogía. Por ello, se suceden también similitudes y coincidencias entre los pensadores que han tratado de esas cuestiones. Ahora bien, lo que otorga especial interés a un autor clásico es la virtualidad de sus planteamientos para enfocar y dar respuesta a los problemas del presente. Esa circunstancia es la que motiva el interés por las ideas y la obra de Francisco Suárez, porque muchas de sus reflexiones sobre el derecho y la política siguen manteniendo vigencia para la cultura jurídica actual.

Se justifica, de este modo el que, cuatro siglos después de su muerte, se pueda aludir a la modernidad de Suárez en su faceta de filósofo y teórico del derecho. Francisco Suárez fue, en su tiempo, una de las principales figuras de la denominada "Escuela Española del Derecho Natural y de Gentes". Esa ubicación doctrinal invita a analizar aquellos aspectos de su doctrina, que gestándose en la atmósfera de la cultura teológica, filosófica y jurídica de nuestro pensamiento clásico, tuvieron en la expresión suareciana la virtualidad de anticipar inquietudes y planteamientos fértiles para el presente.

En las consideraciones que siguen trataré de poner de manifiesto el interés que se desprende de las reflexiones de Francisco Suárez sobre la dimensión social del 
derecho. En esas reflexiones suarecianas se avanzan ideas que, en cierto modo, preludian tesis contemporáneas vinculadas a una concepción institucional del Derecho

\section{Premisas para una lectura del De Legibus en clave institucionalista}

En la historiografía suareciana se suele ponderar, con buenas razones para ello, la contribución de este ilustre jesuita para delimitar el concepto de ley y sus rasgos informadores básicos. La mayor parte de estos estudios tienden a poner de relieve la destacada aportación de Suárez para el estudio individualizado de la ley. Mucho menos frecuente ha sido, sin embargo, el estudio de cuanto se debe a Suárez en la consideración teórica de las leyes en su pluralidad, o sea, en su dimensión relacional conformadora de un sistema normativo ${ }^{2}$. Esta es, precisamente, la perspectiva de análisis que deseo explorar en las reflexiones subsiguientes.

Una consideración atenta del De legibus permite advertir que el propósito de su autor no quedó limitado al análisis de las leyes, en su singularidad, sino que quiso evidenciar su sentido orgánico y sistemático, a partir de un enfoque del orden jurídico en su conjunto. Este planteamiento hace de Suárez un anticipador de algunas de las tesis de la teoría institucional del derecho.

Es notoria la relevancia doctrinal del institucionalismo en el pensamiento jurídico del siglo XX, en el que gozó de dos momentos de especial relevancia: el que corresponde a las primeras décadas del siglo y que se haya representado por las aportaciones de autores tan influyentes como, entre otros, Joseph Delos, Georges Gurvitch, Maurice Hauriou, Georges Renard, Santi Romano; y el renovado interés adquirido al declinar la pasada centuria gracias, sobre todo, a la obra de Neil MacCormicky Ota Weinberger ${ }^{3}$. Frente al formalismo jurídico, la teoría institucional del derecho supuso la reivindicación de los aspectos sociales y comunitarios de la normatividad jurídica y, asimismo, la estructura orgánica e interdependiente de la normatividad surgida de esos entes sociales.

\footnotetext{
${ }^{2}$ Es probable que la contribución más decidida a subrayar la sistematización normativa aportada por Suárez sea, todavía, el libro de G. AMBROSETt। (1948) La filosofia delle leggi di Suárez: il sistema, Roma, Studium.

3 Cfr. A. E. PÉREz LuÑo (2007) Trayectorias contemporáneas de la Filosofía y la Teoría del Derecho, Madrid, Tébar Flores, 23 ss.
} 
Francisco Suárez tiene presente, a lo largo de su entera reflexión sobre las leyes, la inmediata referencia de éstas hacia la comunidad social de la que han surgido y para cuya regulación han sido promulgadas. Esta actitud intelectual encierra un principio metodológico que reviste especial significación para una correcta inteligencia de la postura doctrinal suareciana. En efecto, el título de su obra así como los fines de la misma explícitamente enunciados en su proemium han determinado el que, como ya he indicado supra, frecuentemente se haya considerado la totalidad del tratado como una reflexión sobre las leyes en su pluralidad significativa, pero siempre enjuiciadas de forma individualizada e inorgánica. Es probable que haya sido Norberto Bobbio quien, de forma más rotunda, sustentó esta tesis. Indica Bobbio, en el pórtico de su Teoria dell'ordinamento giuridico, que el De legibus de Francisco Suárez era uno de los más conspicuos ejemplos históricos de una concepción del derecho centrada en la norma, como elemento primario, aislado y autosuficiente, con la consiguiente pérdida de la perspectiva de conjunto del orden jurídico ${ }^{4}$.

El detenido análisis del De legibus permite, no obstante, comprobar la voluntad de Suárez por dotar a su consideración sobre las leyes de un estudio global que hace posible fijar los conceptos y elementos comunes a diversos sectores en los que la legislación se manifiesta. Esto no obedece tan sólo a un propósito de exactitud terminológica, sino que, en mi opinión, es fruto de una profunda intuición del eximio jesuita sobre la necesidad de ofrecer una visión estructural de las leyes, esto es, de plasmar la dinámica de sus relaciones en el seno del orden jurídico.

Es éste un rasgo que caracteriza el entero quehacer metodológico de Suárez. Suárez es consciente de la no coincidencia entre la noción general del derecho con las normas que en ella se comprenden. Al estudiar los caracteres comunes a los distintos tipos de leyes advierte cómo por encima de su variedad existen unos principios directivos que las configuran como una entidad unitaria, esto es, como un ordenamiento jurídico. Esta observación le hace ser consciente de que no puede elaborarse un concepto adecuado de las leyes sin atender a la vez al sistema del que forman parte y a cuya reglamentación se dirigen. Tal circunstancia impulsa a preguntar si en función de estas premisas sería legítimo avanzar una interpretación del pensamiento de Suárez "sub specie institutionis".

La respuesta afirmativa parece desprenderse de los planteamientos doctrinales de Joaquín Ruiz-Giménez, quien incluye a Suárez entre los precedentes históricos

${ }^{4}$ N. BоввІо (1960) Teoria dell'ordinamento giuridico, Turín, Giappichelli, 4. 
de la concepción institucional del Derecho, al subrayar la dimensión comunitaria del Derecho y de la potestad legislativa, así como una magna visión institucional de la Comunidad y del Derecho internacionals.

Quienes han mantenido la tesis contraria, califican la concepción social suareciana como inorgánica, imputando a Suárez el considerar la multitud informe, anterior a toda organización, como "sui iuris", persona moral sujeto de autoridad y apta para administrarse a sí misma ${ }^{b}$.

Es evidente que en el tratamiento unitario de las leyes al que dedica el libro primero de su Tractatus sobre las leyes, se advierten algunos principios que permiten predicar la noción de ordenamiento respecto del pensamiento jurídico suareciano. Es más, se dan en el planteamiento de Suárez algunos de los rasgos que, según la concepción institucional del derecho, caracterizan la noción de ordenamiento jurídico.

Por ordenamiento jurídico se entiende, en su más amplia acepción, la sociedad organizada en forma autónoma de acuerdo con determinados fines y bajo la dirección de una autoridad, en una estructura normativa permanente ${ }^{7}$.

5 J. Ruiz-Giménez CoRTÉs (1944) La concepción institucional del Derecho, Madrid, Instituto de Estudios Políicos, 73-74.

"Así parece desprenderse de la interpretación de E. Guerrero (1948) "Precisiones del pensamiento de Suárez sobre el primer sujeto del poder y sobre la legítima forma de su transmisión al Jefe del Estado": Razón y Fe 48/138 (Francisco Suárez: El hombre. La obra. El influjo) 443-477 (cita 446). En sentido análogo, al estudiar la doctrina jurídica suareciana, se pronunció J. T. Delos (1929) La société internationale et les principes du droit public, París, Pédone, 236 ss.

7 Sobre el concepto de ordenamiento jurídico en relación con el de institución vid. J. T. Delos (1931) "Théorie de I'Institution": Archives de Philosophie du Droit et Sociologie juridique, 1-2, 97ss., A. DesqueYRat (1933) L'institution, le droit objectif et la technique positive, París, Sirey, M. HAURIOU (21921) Précis de Droit Administratif et de Droit Public, París, Sirey, 133 ss., J. I. Hübner Gallo (1951) Introducción a la Teoría de la Norma Jurídica y la Teoría de la Institución, Santiago (Chile), Jurídica de Chile, 170 ss., G. Morin (1931) "Vers la révision de la Technique juridique. Le concept d'institution": Archives de Philosophie du Droit et Sociologie juridique, n. 1-2, 73 ss., G. RenARD (1939) La philosophie de l'institution, París, Sirey, J. RuIz-GIMÉnEZ Cortés (1944) La concepción institucional del Derecho, cit. 48 ss., S. ROMANO (21945) L'ordinamento giuridico, Florencia, Sansoni (traducción al castellano de S. Martín-Retortillo y L. Martín-Retortillo, Madrid 1963, Instituto de Estudios Políticos). Entre las más recientes versiones renovadoras de la teoría institucional del Derecho debe citarse la obra de $\mathrm{N}$. MacCormick y O. WeinBerger (1986) An Institutional Theory of Law, Dordrecht (Países Bajos), Reidel. Del capítulo XI de esta obra sobre "Los límites de la racionalidad en el razonamiento jurídico", existe traducción castellana de M. Atienza y J. Ruiz Manero en J. Betegón y J. R. de PÁramo (1990) Derecho y Moral. Ensayos analíticos, Barcelona, 9 ss. 
Para Suárez el derecho se realiza en un ordenamiento estable de las leyes dirigido hacia el bien común por la autoridad. Un examen de su propia doctrina permitirá calibrar el alcance de sus planteamientos, analizados con referencia a los elementos informadores de la noción de ordenamiento jurídico propuesta.

1) Francisco Suárez advirtió la necesidad de referir el fenómeno jurídico al cuerpo social, asumiéndolo como manifestación de la naturaleza social del ser humano. A su juicio, lo que caracteriza a la ley por su propia esencia es el ser

precepto común, es decir, impuesto a una comunidad o pluralidad de hombres ${ }^{8}$, y añade No existe la menor duda de que la palabra ley significa un precepto de carácter público impuesto a una determinada comunidad, y no a una y otra persona individualmente considerada. ${ }^{9}$

2) Siguiendo un orden lógico de exposición, Suárez se pregunta por los caracteres que debe reunir esa comunidad social para ser considerada como destinataria de la ley, es decir, para su peculiar organización autónoma. Suárez muestra aquí su penetrante sentido jurídico al señalar la interrelación existente entre las distintas formas de comunidad social y sus respectivos ordenamientos jurídicos.

Suárez comienza por distinguir la comunidad del género humano de la comunidad política o mística unida moralmente en grupo a través de vínculos especiales ${ }^{10}$. A la primera comunidad se refiere la ley natural que mediante la luz de la razón es propuesta a cada hombre. Por lo que respecta a las comunidades políticas, cabe distinguir dos tipos: perfectas e imperfectas. Caracteriza a las primeras su capacidad normativa porque toda comunidad perfecta constituye un verdadero cuerpo político gobernado a través de una auténtica jurisdicción, dotada de fuerza coactiva, que es la que establece las leyes ${ }^{11}$. Lo que significa que la comunidad es perfecta en cuanto se constituye en ordenamiento jurídico con autonomía propia. Se llama comunidad perfecta -escribe Suárez- a la que es capaz de gobernarse políticamente, y como tal es autosuficiente en esta esfera ${ }^{12}$.

${ }^{8}$ De legibus, I, 6, 8, ... dicendum est de ratione legis ... esse ut sit praeceptum commune, id est, comnmunitati seu multitudini hominium impositum.

${ }^{9}$ De legibus, I, 6, 10, ... non est dubium quin nomine legis significetur praeceptum publicum communitati alicui et non tantum uni vel alteri personae singulariter impositum.

${ }^{10}$ De legibus, I, 6,18.

$"$ De legibus, I, 6, 21.

${ }^{12}$ De legibus, I, 6, 19. 
Ya Aristóteles ${ }^{13}$ y Tomás de Aquino ${ }^{14}$ habían enseñado que la ciudad es una comunidad perfecta, pero Suárez, mostrando una vez más la penetración de sus construcciones, revela cómo el concepto de comunidad perfecta, y, por tanto, el de ordenamiento jurídico, es más amplio que el de ciudad. "A fortiori" mantiene que también serán perfectas las comunidades de rango superior a la ciudad, como los reinos y cualquier otra forma de comunidad de la que la ciudad forma parte.

Comunidad perfecta es también la sociedad religiosa por haber sido Dios mismo el que la instituyó bajo un jefe que Él designó y con un lazo de unión dirigido al fin sobrenatural ${ }^{15}$. Tal fue, en otro tiempo, la Sinagoga y luego la Iglesia fundada por Cristo y con sujeción a las leyes divino-positivas y capacidad para promulgar sus propias normas: las leyes canónicas.

Pero para Suárez la noción de comunidad perfecta no se circunscribe al Estado o a la Iglesia, como erróneamente interpretó Recaséns Siches ${ }^{16}$. De lo expuesto anteriormente se desprende que para Suárez la noción de comunidad perfecta no se identifica con el Estado. En efecto, a juicio de Suárez, existen dos tipos de comunidades perfectas:

Unas se denominan reales o locales, ya que se encierran dentro de fronteras fijas físicamente localizadas, como son una ciudad o un reino. Otras, por el contrario, reciben el nombre de personales, en razón a que en ellas se tiene más en cuenta las personas que el territorio, como es el caso, por ejemplo, de una orden religiosa, de una cofradía, etc., que pueden constituir también perfectas comunidades, siempre que posean una constitución definida y unión moral17.

Suárez no parte, pues, de la idea de Estado para su concepto de la comunidad perfecta, ni siquiera del de "civitas", como era habitual en la tradición aristotélico-tomista. En su construcción el Estado representa una forma de comunidad perfecta territorial, pero no la única, puesto que por debajo de ella lo es también la ciudad y otras formas comunitarias superiores a la ciudad.

\footnotetext{
${ }^{13}$ Política, lib. I, cap. 1, 1.252 a 5.

${ }^{14}$ Summa theologica, I, II, q. 90 , a. 2 , c.

${ }^{15}$ De legibus, I, 6, 18.

${ }^{16}$ L. ReCAsÉns Siches (21947) La Filosofía del Derecho de Francisco Suárez (Barcelona 1927), Ciudad de México, 126.

${ }^{17}$ De legibus, I, 6, 19.
} 
Esto explica el por qué Suárez podía referirse a una relatividad en la perfección comunitaria, ya que siendo las comunidades territoriales y personales en sí mismas perfectas, no obstante al formar parte unas de otras son en tal aspecto imperfectas no en sentido absoluto, sino comparativa y relativamente ${ }^{18}$. Así, Suárez se anticipaba y resolvía uno de los problemas cruciales de la teoría institucional: el de la pluralidad de ordenamientos jurídicos y sus relaciones. En efecto, la pluralidad de comunidades perfectas admitidas por Suárez implica un reconocimiento de una pluralidad de ordenamientos jurídicos, de carácter territorial unos (supra-estatales, estatales, regionales, locales...); personales otros (comunidades religiosas, profesionales, asistenciales...). Aparte de la Iglesia que es también comunidad perfecta con ordenamiento jurídico propio, pero de especiales características determinadas por su origen y finalidad. Pero el pensamiento de Suárez no se detiene aquí, sino que propone una solución armónica al problema de las relaciones de dependencia entre los diversos ordenamientos jurídicos.

Suárez opta por reconocer un mayor grado relativo de perfección, correlativo a la menor dependencia de cada comunidad social respecto a las otras. Existe una diferencia cuantitativa, no cualitativa, entre las diversas comunidades $y$, consiguientemente, entre los diversos ordenamientos jurídicos. A partir de esa distinción que implica una cierta dependencia, se regulan las relaciones entre las diversas comunidades, de forma que el grado de autonomía reconocido a todas ellas en virtud de su perfección no sea obstáculo para la consecución de fines sociales superiores. Esta tesis pudiera entenderse como una genial anticipación de las sostenidas, siglos más tarde, por Capograssi ${ }^{19}$ y Del Vecchio ${ }^{20}$ al establecer las relaciones de los ordenamientos jurídicos entre sí, y en especial sus vínculos con el ordenamiento jurídico del Estado.

Frente a los caracteres de organización y autonomía que califican a la comunidad perfecta, la comunidad imperfecta, ejemplificada por Suárez en la familia, es concebida como una entidad social que no se basta a sí misma, carente, por tanto, de auténtica capacidad de jurisdicción ${ }^{21}$.

\footnotetext{
${ }^{18}$ De legibus, I, 6, 19.

19 "Note sulla molteplicità degli ordenamenti giuridici", en G. CAPOGRASSI (1959) Opere, Milán, Giuffré, 4, 181 ss. y "Studi sull'esperienzia giuridica", en G. CAPOGRASSI (1959) Opere, cit., 2, 209 ss.

${ }^{20}$ G. DEL VECCHIO (1932) "Stato e societá degli Stati": Rivista internazionale di filosofia del diritto, 12, 14.

${ }^{21}$ De legibus, I, 6, 20-22.
} 
Este punto muestra, una vez más, el realismo suareciano, pues se desprende de su pensamiento que hace depender la potestad de jurisdicción de la autonomía sociológicamente verificable de los núcleos humanos de los que tal cualidad deba predicarse.

3) Pero no basta la existencia de un cuerpo social con potestad normativa autónoma, para que pueda hablarse de comunidad perfecta y, por ello, de ordenamiento jurídico. Para Francisco Suárez esa organización social autónoma carecería de sentido si no se propusiera una obra común a realizar; si no hallase una idea directriz impulsora de todos sus esfuerzos. Ese fin de toda agrupación humana con capacidad normativa es el bien común, que constituye la dimensión teleológica de la ley, o su fin intrínseco, intrinsecum finem legis, en expresión del propio Suárez ${ }^{22}$.

Las normas que se imponen a la comunidad deben dirigirse a su provecho, pues de otra forma serían desordenadas. La subordinación de los intereses particulares al bien común es fruto de una necesidad lógica, porque la parte debe acomodarse al todo. A la vez, constituye un imperativo moral, pues la ley es regla común a toda conducta moral. Luego el principio fundamental del comportamiento moral debe ser también el primer principio de la ley. De tal forma que siendo la felicidad el principio impulsor de las obras morales, lo será también del obrar social comunitario, traduciéndose aquí la felicidad en la idea de bien común. El bien común o prosperidad de la comunidad constituye para ésta el fin último en su esfera, concluye Suárez ${ }^{23}$.

4) Si el bien común representa la causa final de la potestad legislativa, la autoridad supone su causa eficiente. Según Suárez, pertenece a la esencia de toda ley el dimanar de aquellas autoridades que dirigen la comunidad en la que se promulga.

La reunión de un grupo de seres humanos en torno a una idea directiva a realizar, la propia organización de un medio social, no pueden concebirse sin una autoridad que se constituya en elemento rector. Por ello, sostenía Renard que la autoridad es un principio inmanente a la institución: no son los hombres quienes ejercen sobre ella su autoridad; es la propia comunidad social quien la ejerce por medio de los hombres que la encarnan ${ }^{24}$.

\footnotetext{
${ }^{22}$ De legibus, I, 7, 1.

${ }^{23}$ De legibus, I, 7, 4 .

${ }^{24}$ (1930) La théorie de l'institution. Essai d'ontologie juridique, París, Sirey, p. 318.
} 
En toda comunidad-escribía Suárez-existe un poder soberano en su esfera: en la Iglesia, el Sumo Pontífice; en los reinos temporales, el rey; en las repúblicas que se gobiernan aristocráticamente (es decir, por sí mismas), toda la comunidad. No puede haber en verdad un cuerpo sin cabeza, a no ser mutilado o monstruoso. ${ }^{25}$

5) Por último, las comunidades representan en el derecho, como en la Historia, la categoría de la duración. Como acertadamente mantenía Hauriou, una organización, cualquiera que sea, no llega a ser institución si no se muestra durable ${ }^{26}$.

Suárez atribuyó tanta importancia al requisito de la estabilidad y permanencia del derecho que, se ha tenido ocasión de indicar supra, recogió este requisito en su definición de la ley. En la fórmula suareciana la estabilidad o persistencia asume una importancia relevante y dedica a la estabilidad de la ley todo el capítulo décimo del libro primero del De legibus ${ }^{27}$.

Tres son las causas a que alude Suárez para fundamentar la estabilidad del precepto legal:

a) La primera se refiere a la autoridad, en su encarnación personal, porque la ley no se extingue cuando ésta es reemplazada o desaparece con la muerte. Habida cuenta de que, en las leyes humanas, la potestad legislativa se halla en la república, como ésta no desaparece por la muerte de alguno de sus miembros, tampoco por la muerte de la autoridad. Si la comunidad confirió a sus gobernantes la potestad de dar normas, les dio también la facultad de que aquéllas no se extinguieran con su muerte;

b) La segunda se basa en los destinatarios, porque, siendo la comunidad, en principio, perpetua y siempre la misma aunque sucesivamente varíen quienes la integran, sus normas obligan a toda la comunidad en todos sus miembros presentes y futuros;

c) La tercera es de parte de la misma ley, porque una vez promulgada es perpetua hasta que se revoca, o se muda, de tal manera su materia o causa que deja de ser justa. De otro modo -señala Suárez- la continua mudanza de las

${ }^{25}$ De legibus, I, 8, 9

26 Précis de Droit Administrati et de Droit Public, cit., p. 132.

${ }^{27}$ De legibus, I, 12, 1. 
leyes supondría el detrimento de la propia estabilidad de las comunidades sociales. ${ }^{28}$

Pero para Suárez la permanencia no se traduce en inmovilismo de las instituciones sociales $y$, consiguientemente, en inmovilismo del derecho, sino en la exigencia de la imprescindible estabilidad en el funcionamiento del orden jurídico, que viene requerida como suprema garantía de seguridad y certeza en la vida del derecho.

\section{Conclusión: el ideario jurídico de Suárez y su valoración desde el presente ante la conmemoración del cuarto cente- nario de su muerte}

Al cumplirse los tiempos del cuarto centenario de la muerte de Francisco Suárez, su figura sigue siendo digna de memoria y de promover el reconocimiento de la cultura jurídica de nuestro tiempo. Esa conmemoración debiera huir de cualquier tentación grandilocuente, de todo intento de magnificar o mitificar al jesuita granadino. Se aviene mejor con lo que fue su personalidad, mantener viva su memoria a través de la reflexión serena y del estudio. Tenía razón Enrique Gómez Arboleya cuando afirmaba que Suárez se encuentra tan velado con los brillos de su fama como otros con las nieblas del olvido ${ }^{29}$.

La conmemoración de Francisco Suárez se halla justificada, en definitiva, porque su pensamiento y su obra jurídica mantienen intactos su interés y su vigencia. Por ello, estas reflexiones han querido apartarse de una exhumación retrospectiva, de una mera indagación de la arqueología del saber suareciano. Frente a ese enfoque, se ha tratado de ofrecer un enfoque prospectivo del legado jurídico de Suárez. En este estudio he procurado situarle en su tiempo y en el nuestro, ubicándolo en el contexto de nuestros clásicos iusnaturalistas, pero, al propio tiempo, proyectando su doctrina sobre alguno de los principales problemas actuales de la filosofía y de la teoría del derecho.

\footnotetext{
${ }^{28}$ De legibus, I, 4,11 y l, 10,6-12. Para una lectura renovadora de las tesis de Suárez sobre la interpretación de la ley, la validez del derecho y las funciones de la dogmática jurídica, cfr. los trabajos de E. GARZÓN VALDÉS (1977) "Las palabras de la ley y su interpretación: algunas tesis de Francisco Suárez": Dianoia. Anuario de Filosofía, n 23, 30-41 y "Algunos modelos de validez normativa", ibid., 73 ss.

${ }^{29}$ E. Gómez Arboleya (1946) Francisco Suárez, S.I., Granada, Universidad de Granada, p. XIII.
} 
Esta lectura suareciana, en clave de presente, ha intentado evitar el anacronismo que supondría poner en la mente o en la boca de Suárez, ideas o palabras que él jamás pudo pensar o expresar, por hallarse fuera de su tiempo y de su espacio cultural. La consciencia histórica de las categorías jurídicas no consiente transfigurar a un teólogo del Barroco en un filósofo del derecho contemporáneo. Algunas de las inquietudes y de los planteamientos de Suárez son ajenos a nuestra realidad. La solvente y relevante obra de Suárez sobre el derecho no oculta desde su propio título, la aspiración transcendente que la informa: es un Tratado de las leyes y de Dios legislador. Hoy sin embargo los métodos habituales de hacer filosofía y teoría del derecho se mueven en el plano de la inmanencia.

Estas cautelas historiográficas no impiden que, al propio tiempo, se reconozca que muchas de las ideas y de las tesis de Suárez siguen manteniendo su validez y ese es, precisamente, el motivo por el que nos siguen interesando. No parece ocioso recordar aquí la penetrante observación de Xabier Zubiri

el pasado, es, por lo pronto, algo que sólo puede ser entendido desde un presente. El pasado, precisamente por serlo, no tiene más realidad que la de su actuación sobre un presente. De suerte que nuestra actitud ante el pasado depende pura y simplemente de la respuesta que se dé a la pregunta: ¿Cómo actúa sobre el presente?30.

En distintos momentos de este ensayo, he aludido al reproche de Michel Villey a la modernidad de Suárez y a su crítica de las tesis suarecianas anticipadoras del positivismo jurídico y del neopositivismo. Mi disconformidad con Villey en lo que atañe a esa crítica, estriba en que puesto que, como he intentado evidenciar, Suárez nunca se apartó del iusnaturalismo, que mal se aviene con lo que son los presupuestos nucleares del positivismo jurídico y del neopositivismo. Esa discrepancia no me impide, sin embargo, coincidir plenamente con Villey, aunque desde una valoración inversa, en considerar a Suárez como un precursor del pensamiento jurídico contemporáneo.

${ }^{30}$ X. ZUBIRI (1959) Naturaleza, Historia, Dios, Madrid, Nacional, 286. 